\title{
Editorial
}

\section{How important is early detection and prompt treatment in congenital hypothyroidism patients?}

Vivian Soetikno

In Indonesia, the incidence of congenital hypothyroidism from 2000 to 2014, recorded around 1:2,531 births and $>70 \%$ of congenital hypothyroidism was diagnosed after children aged over 1 year resulting in permanent mental retardation and intelligence disorders. For instance, if the birth rate is around 5 million/year and the incidence of congenital hypothyroidism is 1:3,000 births, there will be more than 1,600 babies with congenital hypothyroidism per year which, will accumulate annually and this will certainly increase the burden of the country. ${ }^{1}$

Congenital hypothyroidism is an endocrine disorder that most common treatable and preventable causes of mental retardation and intelligence disorders. Many studies have proven that to prevent mental retardation and intelligence disorders in congenital hypothyroidism is early detection through newborn screening and prompt hormonal replacement therapy in the shortest possible time. ${ }^{2-4}$ Indeed, newborn screening to detect congenital hypothyroidism has been introduced since 1974 and today this program has been integrated in the public healthcare systems of most countries worldwide. Though in 2014, the Minister of Health of the Republic of Indonesia has decreed the implementation of congenital hypothyroidism screening, but in reality it failed due to insufficient financial support as well as lack of awareness of the importance of the screening. ${ }^{5}$ These have triggered many undetected and delayed diagnosed of congenital hypothyroidism, which in turn leads to delayed treatment. The majority of newborns with congenital hypothyroidism show no obvious symptoms, making it difficult to diagnose clinically, as well. This is because most newborns still have residual thyroid function from transplacental passage of maternal thyroid hormone and also due to the signs and symptoms of hypothyroidism are relatively nonspecific. ${ }^{2,5}$
Untreated and/or delayed treatment of congenital hypothyroidism will show a variety of manifestations, including late linear growth and bone maturation, in addition to mental retardation and intelligence disorders. ${ }^{3}$ Previous studies have demonstrated that treatment with hormone replacement therapy starting within the first two to three weeks of life resulted in normal levels of intelligence and linear growth in children with congenital hypothyroidism. ${ }^{4}$ In addition, a systematic review in 2016 concluded that initiating treatment early in the first day of life is crucial in ensuring the best neurodevelopmental outcome in patients with congenital hypothyroidism. ${ }^{3}$ Najmi et $a^{6}{ }^{6}$ demonstrated that mean score IQ in both permanent and transient congenital hypothyroidism patients were significantly lower as compared to that in normal healthy patients, which negatively correlated with the treatment initiation time. Pulungan et $\mathrm{al}^{7}$ conducted a study in patients with primary congenital hypothyroidism to test whether there was a relationship between cognitive function and delayed diagnosis and treatment of congenital hypothyroidism. Almost all patients were diagnosed at the age of over 1 month with a median age of 9 years and the median age at the initiation of therapy was 1.5 years. Although they were able to demonstrate there was a negative correlation between full-scale IQ, verbal IQ, and performance IQ and the age at treatment initiation, the correlation between full-scale IQ and verbal IQ was not reached a statistically significant. They concluded that the delayed initiation of thyroid hormone replacement therapy in congenital hypothyroidism patients was due to the unavailability of the newborn screening program that would ultimately disrupt the intelligence of children with congenital hypothyroidism.

Therefore, it is important to do early detection by implementing a newborn screening program for

Copyright @ 2019 Author. This is an open access article distributed under the terms of the Creative Commons Attribution-NonCommercial 4.0 International License (http:// creativecommons.org/licenses/by-nc/4.0/), which permits unrestricted non-commercial use, distribution, and reproduction in any medium, provided the original author and source are properly cited. 
congenital hypothyroidism and prompt treatment so that it can improve the prognosis and quality of life of patients with congenital hypothyroidism since delayed diagnosis and treatment will likely to result in irreversible neuropsychological deficits and although diagnosed early, neurological development will not develop completely if treatment is not optimal in two to three years of life. ${ }^{8}$ Is this still in doubt?

From Medical Journal of Indonesia; Department of Pharmacology and Therapeutic, Faculty of Medicine, Universitas Indonesia pISSN: 0853-1773 • elSSN: 2252-8083

https://doi.org/10.13181/mji.v28i4.4370

Med J Indones. 2019;28:309-10

\section{Corresponding author:}

Vivian Soetikno

E-mail: vivian.soetikno@ui.ac.id

\section{REFERENCES}

1. Indonesian Ministry of Health. InfoDATIN situation and analysis of thyroid disease [Internet]. Jakarta: Indonesian Ministry of Health; 2015 [cited 2019 Nov 23]. Available from: https:// pusdatin.kemkes. go.id/folder/view/01/structure-publikasipusdatin-info-datin.html. Indonesian.

2. Ihsan I, Rini EA. Delayed diagnosis of congenital hypothyroidism in an adolescent results in avoidable complications: a case report. Paediatr Indones. 2017;57(2):108-16.

3. Rahmani K, Yarahmadi S, Etemad K, Koosha A, Mehrabi Y, Aghang $\mathrm{N}$, et al. Congenital hypothyroidism: optimal initial dosage and time of initiation of treatment: a systematic review. Int J Endocrinol Metab. 2016;14(3):e36080.

4. LaFranchi SH. Approach to the diagnosis and treatment of neonatal hypothyroidism. J Clin Endocrinol Metab. 2011;96(10):2959-67.

5. Skrining hipotiroid kongenital. Menteri Kesehatan Republik Indonesia. Peraturan Menteri Kesehatan Republik Indonesia No. 78 Tahun 2014.

6. Najmi SB, Hashemipour M, Maracy MR, Hovsepian S, Ghasemi M. Intelligence quotient in children with congenital hypothyroidism: the effect of diagnostic and treatment variables. J Res Med Sci. 2013;18(5):395-9.

7. Pulungan $A B$, Oldenkamp ME, van Trotsenburg ASP, Windarti $W$, Gunardi H. Effect of delayed diagnosis and treatment of congenital hypothyroidism on intelligence and quality of life: an observational study. Med J Indones. 2019;28(4):396-401.

8. Bongers-Schokking JJ, de Muinck Keizer-Schrama SM. Influence of timing and dose of thyroid hormone replacement on mental, psychomotor, and behavioral development in children with congenital hypothyroidism. J Pediatr. 2005;147(6):768-74. 